\title{
High expression of special AT-rich sequence binding protein-1 predicts esophageal squamous cell carcinoma relapse and poor prognosis
}

\author{
SONGHUI ZHAI ${ }^{1 *}$, JIANXIN XUE ${ }^{2 *}$, ZHENG WANG $^{1}$ and LIJUAN HU ${ }^{3}$ \\ ${ }^{1}$ Department of Pediatrics, West China Second University Hospital, Sichuan University; ${ }^{2}$ Department of Thoracic Oncology, \\ Cancer Center, West China Hospital, Sichuan University; ${ }^{3}$ Department of Immunology, West China School of \\ Basic Medical Sciences \& Forensic Medicine, Sichuan University, Chengdu, Sichuan 610041, P.R. China
}

Received March 30, 2016; Accepted June 21, 2017

DOI: $10.3892 / \mathrm{ol} .2017 .7081$

\begin{abstract}
Previous studies of the roles of special AT-rich sequence binding protein-1 (SATB1) in the development and progression of cancer have suggested that SATB1 promotes cancer cell metastasis. The aim of the present study is to evaluate the role of SATB1 in the progression and prognosis of esophageal squamous cell carcinoma (ESCC). ESCC tissues were collected from 102 patients and SATB1 mRNA expression was measured by reverse transcription-quantitative polymerase chain reaction. The association between expression of SATB1 mRNA with clinicopathological features and prognosis was assessed, and the prognosis of ESCC was evaluated using Kaplan-Meier survival curves. In the 102 ESCC tissues, SATB1 mRNA expression correlated with the clinical tumor node metastasis stage $(\mathrm{P}<0.05)$, but not with any other clinicopathological features (including age, gender, tumor differentiation grade, adjuvant radio/chemotherapy, or the consumption of alcohol and use of cigarettes) $(\mathrm{P}>0.05)$. The disease-free survival (DFS) and overall survival (OS) of patients with high SATB1 expression was decreased compared with those with low SATB1 expression. The present study indicated that SATB1 mRNA expression was associated with the postoperative recurrent and poor prognosis in ESCC. SATB1 may be a novel marker for predicting the recurrent and worse prognosis of ESCC.
\end{abstract}

\section{Introduction}

Esophageal cancer cases are distributed worldwide; its mortality rate ranks sixth among all types of cancer and it is

Correspondence to: Dr Lijuan Hu, Department of Immunology, West China School of Basic Medical Sciences \& Forensic Medicine, 17 Ren Min South Road, Chengdu, Sichuan 610041, P.R. China E-mail: hulijuan@scu.edu.cn

*Contributed equally

Key words: special AT-rich sequence binding protein-1, esophageal squamous cell carcinoma, reverse transcription-quantitative polymerase chain reaction, disease-free survival, overall survival, relapse the fourth most commonly occurring cancer in China $(1,2)$. China is among the highest risk areas of esophageal cancer, where $\sim 90 \%$ of cases are squamous cell carcinoma (SCC) (3). The 5-year survival rate and quality of life remain low (3). However, the molecular mechanisms underlying the initiation and progression of esophageal SCC (ESCC) remain unclear.

Special AT-rich sequence binding protein-1 (SATB1), a tissue-specific nuclear matrix binding protein, was identified in 1992 (4). SATB1 is primarily expressed in thymocytes, and also the expression of SATB1 in the basal layer of the epidermis is regulated by p63 $(5,6)$. SATB1 can regulate gene expression by folding chromatin into loop domains and tethering DNA domains to the SATB1 network structure $(7,8)$. Under normal conditions, SATB1 is expressed at low levels in cells and tissues, but is overexpressed in a variety of malignant tumors, including laryngeal squamous cell carcinoma, endometrial cancer, hepatocellular carcinoma, rectal cancer, cutaneous malignant melanoma, gastric cancer, prostate cancer, lung cancer and cutaneous T-cell lymphoma (7,9-20). The expression of SATB1 has been examined in esophageal adenocarcinoma and is an independent prognostic factor (20). In several types of cancer, including laryngeal squamous cell carcinoma, endometrial cancer, hepatocellular cancer and lung cancer, high expression of SATB1 promotes tumor growth and metastasis, and is a negative prognostic factor (7,9-20). SATB1 can regulate the expression of $>1,000$ genes involved in the processes of DNA organization, proliferation and apoptosis $(8,9)$. SATB1 has been demonstrated to serve roles in malignancies, in addition to malignant transformation $(7,20)$.

The present study aimed to explore the role of SATB1 in ESCC by investigating the association between SATB1 mRNA expression and prognosis, and recurrence in 102 patients with ESCC following surgery.

\section{Materials and methods}

Tissue samples, patient data and follow-up. A total of 102 tissue samples of ESCC were obtained from patients (78 male, 24 female) undergoing surgery at the Department of 
Thoracic Oncology, West China Hospital, Sichuan University (Chengdu, China) between March 2010 and July 2014. Patient median age was 60.5 years old (range, $39-81$ years old). All specimens were immediately frozen in liquid nitrogen and stored at $-80^{\circ} \mathrm{C}$ until RNA extraction. All human ESCC tissue samples were obtained and handled in accordance with an approved Institutional Review Board application (Ethics Committee of Sichuan University). Written informed consent was obtained from all patients.

All patients were diagnosed with primary ESCC based on pathological assessment and had undergone a complete surgical resection (R0). Patients who underwent non-curative resection (R1), succumbed to postoperative complications, missed valid follow-up conditions or lacked clinical data were all excluded from the present study. No patients received chemotherapy or radiotherapy prior to surgery. The clinical stage and histologic grade of the tumor was defined according to the 7th edition of the Tumor Node Metastasis (TNM) classification of the International Union Against Cancer (21). Follow-up began on the date of surgery and ended in July 2014. The median follow-up was 35.5 months (range, 6-70 months). Regular history and physical examinations were performed in all patients every 3 months during the first 2 years after surgery and then every 6 months thereafter.

$R N A$ extraction and reverse transcription-quantitative polymerase chain reaction ( $R T-q P C R)$. Total RNA was extracted from cancerous specimens using TRIzol reagent (Invitrogen; Thermo Fisher Scientific, Inc., Waltham, MA, USA). A total of $5 \mu \mathrm{g}$ of each RNA sample was reverse transcribed into complementary DNA using the Prime-Script ${ }^{\mathrm{TM}}$ one step RT-PCR kit (Takara Bio, Inc., Otsu, Japan). SATB1 expression level was determined by RT-qPCR using the following primer sequences: forward, 5'-GTGGAAGCC TTGGGAATCC-3' and reverse, 5'-CTGACAGCTCTTCTT CTAGTT-3'. $\beta$-actin was used as an internal control, using the following primer sequences: forward, 5'-CTGGCA CCACACCTTCTACAATG-3' and reverse, 5'-CCTCGT AGATGGGCACAGTGTG-3'. The RT-qPCR reaction was performed with an initial $95^{\circ} \mathrm{C}$ denaturation step for $10 \mathrm{~min}$, followed by 40 cycles of $95^{\circ} \mathrm{C}$ for $30 \mathrm{sec} 60^{\circ} \mathrm{C}$ for $30 \mathrm{sec}$ and $72^{\circ} \mathrm{C}$ for $30 \mathrm{sec}$ at for 40 cycles using theABI7500 system (Applied Biosystems; Thermo Fisher Scientific, Inc.) and the SYBRGreen PCR Master Mix (Takara Bio, Inc.). SATB1 mRNA levels were normalized to $\beta$-actin by the $2^{-\Delta \Delta C q}$ method (22).

Statistical analysis. All statistical analyses were performed using SPSS software, version 17.0 (SPSS, Inc., Chicago, IL, USA). Spearman's rank correlation coefficient test was used to analyze the correlation between SATB1 expression in different groups of patients. Comparison of continuous data was performed with an independent t-test between two groups, whereas the correlation among categorical variables was analyzed using a $\chi^{2}$ test. Disease-free survival (DFS) and overall survival (OS) analyses were performed with the Kaplan-Meier estimator and log-rank tests. Multiple factor analyses were performed using Cox regression models to evaluate prognostic factor for patients with ESCC. $\mathrm{P}<0.05$ was considered to indicate a statistically significant difference.

\section{Results}

Patient clinicopathological characteristics. A total of 102 patients with ESCC were included in the current study (78 male, 24 female). Their median age was 60.5 years old (range, 39-81 years old). A total of 35 patients (34.3\%) had lymph node metastases and none had distant nodal metastases (Table I).

Association between SATB1 expression and clinicopathological characteristics. According to the average expression (the median value $=1.39$ ) of SATB1 mRNA, the 102 patients with ESCC were split into two groups. A high expression group with SATB1 mRNA expression above 1.39 and a low expression group with SATB1 mRNA expression below 1.39. A total of $49(48.0 \%)$ specimens exhibited high expression and $53(54.0 \%)$ specimens exhibited low expression of SATB1 mRNA. No significant associations were identified between the expression level of SATB1 and patient age, gender, tumor differentiation grade, adjuvant radio/chemotherapy or the use of alcohol and cigarettes $(\mathrm{P}>0.05)$. However, the expression level was correlated with clinical TNM stage $(\mathrm{P}<0.05)$ (Table I).

High expression of SATB1 $m R N A$ is associated with poor prognosis for patients with ESCC. To reveal whether pathological TNM (pTNM) stage and SATB1 mRNA expression affected postoperative outcome, univariate analyses were performed. The results indicated that SATB1 expression and pTNM stage were associated with postoperative outcome (Table II). Patients with high SATB1 mRNA expression had a shorter OS (median, 34.9 months) compared with those with low SATB1 mRNA expression (median, 40.3 months) ( $\mathrm{P}=0.035$; Table III and Fig. 1A). Multivariate analysis suggested that SATB1 expression was an independent factor associated with OS ( $\mathrm{RR}=2.02 ; 95 \%$ CI: $1.10-3.68, \mathrm{P}<0.05)$.

SATB1 $\mathrm{mRNA}$ expression is associated with the relapse of $E S C C$. The duration of DFS of patients with ESCC with high SATB1 mRNA expression ( $31.53 \pm 16.34$ months) was significantly shorter compared with that of patients with low SATB1 mRNA expression $(37.70 \pm 16.28$ months, $\mathrm{P}=0.029)$ (Table IV and Fig. 1B).

\section{Discussion}

Previous studies have indicated that SATB1 is associated with prognosis in resected upper gastrointestinal tract adenocarcinoma and other tumor forms $(20,23,24)$. Data from the present study revealed that patients with higher SATB1 mRNA expression had a higher rate of relapse. SATB1 expression was detected in ESCC tumor tissues by measuring mRNA expression; high SATB1 mRNA expression was associated with poor DFS and OS, as determined by univariate analysis. Multivariate analysis revealed that high SATB1 expression may be an independent factor for poor prognosis in patients with ESCC following surgery. These results were consistent with another previous report, in which SATB1 expression groups were divided using a semi-quantitative scoring system for staining intensity and the percentage of positive malignant 
Table I. Association between SATB1 expression and clinicopathologic parameters in 102 patients with ESCC.

\begin{tabular}{|c|c|c|c|}
\hline Factor & $\begin{array}{l}\text { SATB1 low expression } \\
(\mathrm{n}=53) \mathrm{N}(\%)\end{array}$ & $\begin{array}{l}\text { SATB1 high expression } \\
\qquad(\mathrm{n}=49) \mathrm{N}(\%)\end{array}$ & P-value \\
\hline Age (mean \pm standard deviation) $)^{\mathrm{a}}$ & $61.5 \pm 7.8$ & $59.5 \pm 10.8$ & $0.310^{\mathrm{b}}$ \\
\hline Age group & & & $0.666^{\mathrm{c}}$ \\
\hline$\leq 61 \mathrm{yrs}$ & $25(47.2)$ & $21(42.0)$ & \\
\hline$>61 \mathrm{yrs}$ & $28(52.8)$ & $28(56.0)$ & \\
\hline Gender & & & $0.475^{\mathrm{c}}$ \\
\hline Male & $39(73.6)$ & $39(79.6)$ & \\
\hline Female & $14(26.4)$ & $10(20.4)$ & \\
\hline Smoking/drinking alcohol & & & $0.701^{\mathrm{c}}$ \\
\hline Never & $17(32.1)$ & 14 (28.6) & \\
\hline Ever and current & $36(67.9)$ & $35(71.4)$ & \\
\hline Family history of ESCC & & & $0.963^{\mathrm{c}}$ \\
\hline No & $37(69.8)$ & $34(69.4)$ & \\
\hline Yes & $16(30.2)$ & $15(30.6)$ & \\
\hline Barium meal examination & & & $0.760^{\mathrm{c}}$ \\
\hline Mushroom type & $10(18.9)$ & $6(12.0)$ & \\
\hline Medullary type & $16(30.2)$ & $16(32.0)$ & \\
\hline Ulcer & $25(47.2)$ & $24(46.0)$ & \\
\hline Mass & 0 & $1(2.0)$ & \\
\hline Coarctation & $2(3.8)$ & $2(4.0)$ & \\
\hline Tumor location & & & $0.908^{\mathrm{c}}$ \\
\hline Upper & $2(3.8)$ & $1(2.0)$ & \\
\hline Middle & $38(71.7)$ & $35(71.4)$ & \\
\hline Low & $13(24.5)$ & $13(26.5)$ & \\
\hline Histological type & & & $0.552^{\mathrm{c}}$ \\
\hline High & $22(41.5)$ & $23(46.9)$ & \\
\hline Middle & $28(50.9)$ & $24(49)$ & \\
\hline Low & $3(5.7)$ & $2(4.1)$ & \\
\hline pT status & & & $0.074^{\mathrm{c}}$ \\
\hline pT1 & $1(1.9)$ & $5(10.2)$ & \\
\hline pT2-4 & $52(98.1)$ & $44(89.8)$ & \\
\hline Lymph node metastasis & & & $0.361^{\mathrm{c}}$ \\
\hline Yes & $16(30.2)$ & $19(38.8)$ & \\
\hline No & $37(69.8)$ & $30(61.2)$ & \\
\hline pTNM stage & & & $0.003^{\mathrm{c}}$ \\
\hline I & $15(28.3)$ & $16(32.7)$ & \\
\hline II & $25(47.2)$ & $10(20.4)$ & \\
\hline III & $13(24.5)$ & $16(32.7)$ & \\
\hline IV & $0(0)$ & $7(14.3)$ & \\
\hline pTNM stage group & & & $0.023^{\mathrm{c}}$ \\
\hline $\mathrm{I}-\mathrm{II}$ & $40(75.5)$ & $26(53.1)$ & \\
\hline III-IV & $13(24.5)$ & 23 (46.9) & \\
\hline Relapse & & & $0.029^{\mathrm{c}}$ \\
\hline No & $33(62.3)$ & $19(38.8)$ & \\
\hline Yes & $20(37.7)$ & $30(61.2)$ & \\
\hline
\end{tabular}

${ }^{\mathrm{a}} \mathrm{Age}$ data are presented as the mean \pm standard deviation. ${ }^{\mathrm{b}}$ Independent $\mathrm{t}$-test. ${ }^{\mathrm{C}}$ Two-sided ${ }^{2} \chi$-test. pT, pathological tumor stage; $\mathrm{pN}$, pathological node stage; pTNM, pathological tumor node metastasis stage.

cells (25). These results verified the importance of the SATB1 gene in ESCC. The current study defined the expression state according to the median value of all ESCC tissues, which may exclude subjective bias. However, it is challenging to obtain a 
Table II. Univariate analyses of prognostic factors in ESCC with respect to OS.

\begin{tabular}{llll}
\hline Factor & RR & $95 \%$ CI & P-value \\
\hline pT status (T1/T2-4) & 1.358 & $0.472-3.908$ & 0.571 \\
pN status (N0/1-3) & 0.517 & $0.203-1.317$ & 0.167 \\
pTNM stage (I-II/III-IV) & 7.25 & $1.62-32.458$ & $0.021^{\text {a }}$ \\
Adjuvant therapy & 1.134 & $0.668-1.924$ & 0.642 \\
SATB1 expression: low/high & 1.928 & $1.128-3.297$ & $0.016^{\text {a }}$
\end{tabular}

${ }^{\mathrm{a}} \mathrm{P}<0.05$. ESCC, esophageal squamous cell carcinoma; OS, overall survival; pT, pathological tumor stage; pN, pathological node stage; pTNM, pathological tumor node metastasis stage.

Table III. Cumulative proportion of OS at different time points.

No. of patients

Group

SATB1 low expression $(\mathrm{n}=53)$

SATB1 high expression $(n=49)$ that succumbed
Cumulative proportion of OS

\begin{tabular}{ccc}
\hline 12 months $(\%)$ & 36 months $(\%)$ & 60 months $(\%)$ \\
88.6 & 63.7 & 54.3 \\
83.6 & 56.0 & 31.5
\end{tabular}

OS, overall survival; SATB1, special AT-rich sequence-binding protein 1.

Table IV. The cumulative proportion of DFS at different time points.

Cumulative proportion of DFS

\begin{tabular}{lcccc} 
Group & N of relapse & 12 months $(\%)$ & 36 months $(\%)$ & 60 months $(\%)$ \\
\hline SATB1 low expression $(n=53)$ & 20 & 86.6 & 76.1 & 51.2 \\
SATB1 high expression $(n=49)$ & 30 & 85.4 & 49.0 & 14.8
\end{tabular}

DFS, disease-free survival; SATB1, special AT-rich sequence-binding protein 1.
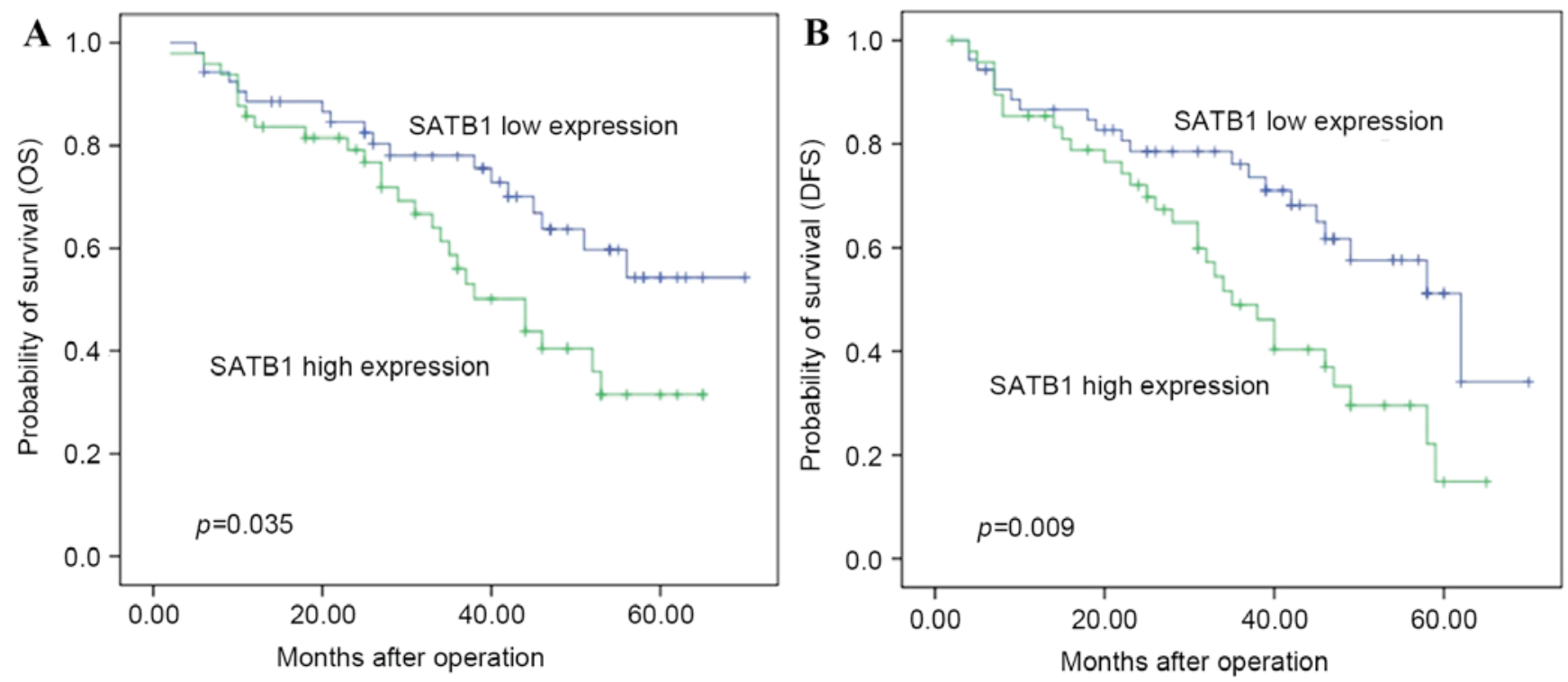

Figure 1. OS and DFS curves of patients with ESCC according to SATB1 mRNA expression status. (A) OS curve, P=0.035; (B) DFS curve, P=0.009. OS, overall survival; DFS, disease-free survival; ESCC, esophageal squamous cell carcinoma; SATB1, special AT-rich sequence-binding protein 1. 
'clean' tumor sample without inflammatory and stromal cells. Cong et al (25) reported that SATB1 expression measured by immunohistochemistry could classify SATB1 expression in tumor cells from inflammatory cells and stromal cells, whereas the results obtained using semi-quantitative systems were not precise. Furthermore, SATB1 expression was identified in inflammatory cells but not in stromal cells (26). SATB1 integrates global epigenetic and transcriptional programs that determine cellular phenotypes, differentiation, and the activity of leukocyte subsets (27). In future studies, more patients at respective pTNM stages will be recruited to define the median level of SATB1 mRNA expression at different stages, explore the expression of SATB1 expression between tumor tissues and inflammatory cells, and investigate the role of SATB1 in the development and prognosis of ESCC.

The incidence of ESCC was different in different regions of the world and the variation has changed over time (2). This suggests that multiple risk factors (genetic and environmental) contribute to the development of ESCC (28-30). Morita et al (30) reported that cigarette smoking and alcohol consumption exhibit synergistic effects on the development of ESCC. Kasagi et al (31) reviewed the clinicopathological characteristics of ESCC in patients $<50$ years old and revealed that the incidence of ESCC was associated with heavy exposure to smoking and/or drinking. Wu et al (32) recruited 718 patients with ESCC in Taiwan and demonstrated that the habitual drinking of alcohol was the strongest predictor for ESCC survival, followed by areca chewing and smoking. In the current study, smoking and drinking was associated with the prognosis of ESCC, but had not with SATB1 mRNA expression, suggesting that other mechanisms participate in ESCC development.

In conclusion, the present study identified that high expression of SATB1 in ESCC was associated with a clinically unfavorable prognosis independent of the patient's disease stage, therefore SATB1 expression may be an independent factor of poor prognosis in ESCC. Further studies are required to elucidate the molecular mechanisms underlying the roles of SATB1 in the progression of ESCC.

\section{Acknowledgements}

The present study was financially supported by grants from the National Natural Science Foundation of China (grant no. 81472808). The authors would like to thank Dr Nan Li (Sichuan University, Chengdu, China) for language editing and proofreading.

\section{References}

1. Parkin DM, Bray F, Ferlay J and Pisani P: Global cancer statistics, 2002. CA Cancer J Clin 55: 74-108, 2005.

2. Yang L, Parkin DM, Ferlay J, Li L and Chen Y: Estimates of cancer incidence in China for 2000 and projections for 2005. Cancer Epidemiol Biomarkers Prev 14: 243-250, 2005.

3. Jemal A, Bray F, Center MM, Ferlay J, Ward E and Forman D: Global cancer statistics. CA Cancer J Clin 61: 69-90, 2011.

4. Dickinson LA, Joh T, Kohwi Y and Kohwi-Shigematsu T: A tissue-specific MAR/SAR DNA-binding protein with unusual binding site recognition. Cell 70: 631-645, 1992.

5. Alvarez JD, Yasui DH, Niida H, Joh T, Loh DY and Kohwi-Shigematsu T: The MAR-binding protein SATB1 orchestrates temporal and spatial expression of multiple genes during T-cell development. Genes Dev 14: 521-535, 2000.
6. Fessing MY, Mardaryev AN, Gdula MR, Sharov AA, Sharova TY, Rapisarda V, Gordon KB, Smorodchenko AD, Poterlowicz K, Ferone G, et al: p63 regulates Satb1 to control tissue-specific chromatin remodeling during development of the epidermis. J Cell Biol 194: 825-839, 2011.

7. Kohwi-Shigematsu T, Poterlowicz K, Ordinario E, Han HJ, Botchkarev VA and Kohwi Y: Genome organizing function of SATB1 in tumor progression. Semin Cancer Biol 23: 72-79, 2013.

8. Cai S, Han HJ and Kohwi-Shigematsu T: Tissue-specific nuclear architecture and gene expression regulated by SATB1. Nat Genet 34: 42-51, 2003.

9. Zhao XD, Ji WY, Zhang W, He LX, Yang J, Liang HJ and Wang LL: Overexpression of SATB1 in laryngeal squamous cell carcinoma. ORL J Otorhinolaryngol Relat Spec 72: 1-5, 2010.

10. Mokhtar NM, Ramzi NH, Yin-Ling W, Rose IM, Hatta Mohd Dali AZ and Jamal R: Laser capture microdissection with genome-wide expression profiling displayed gene expression signatures in endometrioid endometrial cancer. Cancer Invest 30: 156-164, 2012.

11. Tu W, Luo M, Wang Z, Yan W, Xia Y, Deng H, He J, Han P and Tian D: Upregulation of SATB1 promotes tumor growth and metastasis in liver cancer. Liver Int 32: 1064-1078, 2012.

12. Meng WJ, Yan H, Zhou B, Zhang W, Kong XH, Wang R, Zhan L, Li Y, Zhou ZG and Sun XF: Correlation of SATB1 overexpression with the progression of human rectal cancer. Int J Colorectal Dis 27: 143-150, 2012.

13. Chen H, Takahara M, Oba J, Xie L, Chiba T, Takeuchi S, Tu Y, Nakahara T, Uchi H, Moroi Y and Furue M: Clinicopathologic and prognostic significance of SATB1 in cutaneous malignant melanoma. J Dermatol Sci 64: 39-44, 2011.

14. Cheng C, Lu X, Wang G, Zheng L, Shu X, Zhu S, Liu K, Wu K and Tong Q: Expression of SATB1 and heparanase in gastric cancer and its relationship to clinicopathologic features. APMIS 118: 855-863, 2010.

15. Lu X, Cheng C, Zhu S, Yang Y, Zheng L, Wang G, Shu X, Wu K, Liu K and Tong Q: SATB1 is an independent prognostic marker for gastric cancer in a Chinese population. Oncol Rep 24: 981-987, 2010

16. Mao L, Yang C, Wang J, Li W, Wen R, Chen J and Zheng J: SATB1 is overexpressed in metastatic prostate cancer and promotes prostate cancer cell growth and invasion. J Transl Med 11: 111, 2013.

17. Zhou LY, Liu F, Tong J, Chen QQ and Zhang FW: Expression of special AT-rich sequence-binding protein $\mathrm{mRNA}$ and its clinicopathological significance in non-small cell lung cancer. Nan Fang Yi Ke Da Xue Xue Bao 29: 534-537, 2009 (In Chinese).

18. Selinger CI, Cooper WA, Al-Sohaily S, Mladenova DN, Pangon L, Kennedy CW, McCaughan BC, Stirzaker C and Kohonen-Corish MR: Loss of special AT-rich binding protein 1 expression is a marker of poor survival in lung cancer. $\mathrm{J}$ Thorac Oncol 6: 1179-1189, 2011.

19. Zhang S, Gao X, Ma Y, Jiang J, Dai Z, Yin X, Min W, Hui W and Wang B: Expression and significance of SATB1 in the development of breast cancer. Genet Mol Res 14: 3309-3317, 2015.

20. Hedner C, Gaber A, Korkocic D, Nodin B, Uhlén M, Kuteeva E, Johannesson H, Jirström K and Eberhard J: SATB1 is an independent prognostic factor in radically resected upper gastrointestinal tract adenocarcinoma. Virchows Arch 465: 649-659, 2014.

21. Rice TW, Blackstone EH and Rusch VW: 7th Edition of the AJCC cancer staging manual: Esophagus and esophagogastric junction. Ann Surg Oncol 17: 1721-1724, 2010.

22. Livak KJ and Schmittgen TD: Analysis of relative gene expression data using real-time quantitative PCR and the 2(-Delta Delta C(T)) method. Methods 25: 402-408, 2001.

23. Wan F, Cheng C, Wang Z, Xiao X, Zeng H, Xing S, Chen X, Wang J, Li S, Zhang Y, et al: SATB1 overexpression regulates the development and progression in bladder cancer through EMT. PLoS One 10: e0117518, 2015.

24. Han HJ, Russo J, Kohwi Y and Kohwi-Shigematsu T: SATB1 reprogrammes gene expression to promote breast tumour growth and metastasis. Nature 452: 187-193, 2008.

25. Cong QX, Zhang H, Sun SX, Li HF, Wang Y and Jian S: Pilot study special AT-rich sequence-binding protein 1 investigating as a potential biomarker for esophageal squamous cell carcinoma. Dis Esophagus 29: 621-626, 2016.

26. Tesone AJ, Rutkowski MR, Brencicova E, Svoronos N, Perales-Puchalt A, Stephen TL, Allegrezza MJ, Payne KK, Nguyen JM, Wickramasinghe J, et al: Satb1 overexpression drives tumor-promoting activities in cancer-associated dendritic cells. Cell Rep 14: 1774-1786, 2016. 
27. Borghesi L: Hematopoiesis in steady-state versus stress: Self-renewal, lineage fate choice, and the conversion of danger signals into cytokine signals in hematopoietic stem cells. J Immunol 193: 2053-2058, 2014.

28. Song Y, Wang Y, Xu L, Ma J, Chen E, Zang R, Jia W, Tao X and $\mathrm{Hu}$ L: A genetic variant in CHRNB3-CHRNA6 increases risk of esophageal squamous cell carcinoma in Chinese populations. Carcinogenesis 36: 538-542, 2015

29. Chen J, Kwong DL, Cao T, Hu Q, Zhang L, Ming X, Chen J, Fu L and Guan X: Esophageal squamous cell carcinoma (ESCC): Advance in genomics and molecular genetics. Dis Esophagus 28: 84-89, 2015 .

30. Morita M, Kumashiro R, Kubo N, Nakashima Y, Yoshida R, Yoshinaga K, Saeki H, Emi Y, Kakeji Y, Sakaguchi Y, et al: Alcohol drinking, cigarette smoking, and the development of squamous cell carcinoma of the esophagus: Epidemiology, clinical findings, and prevention. Int J Clin Oncol 15: 126-134, 2010.
31. Kasagi Y, Morita M, Otsu H, Kawano H, Ando K, Hiyoshi Y, Ito S, Miyamoto Y, Saeki H, Oki E and Maehara Y: Clinicopathological characteristics of esophageal squamous cell carcinoma in patients younger than 50 years. Ann Surg Oncol 22: 311-315, 2015.

32. Wu IC, Wu CC, Lu CY, Hsu WH, Wu MC, Lee JY, Chou SH, Lee JM, Chou YP, Wu DC and Wu MT: Substance use (alcohol, areca nut and cigarette) is associated with poor prognosis of esophageal squamous cell carcinoma. PLoS One 8: e55834, 2013. 